\title{
An improved model of hybrid multi converter used for grid connected applications
}

\author{
E. Catherine Amala Priya ${ }^{1}$, G. T. SundarRajan ${ }^{2}$ \\ ${ }^{1}$ Sathyabama Institute of Science \& Technology, India \\ ${ }^{2}$ Department of EEE, Sathyabama Institute of Science \& Technology, India
}

\begin{tabular}{l} 
Article Info \\
\hline Article history: \\
Received Aug 26, 2018 \\
Revised Nov 11, 2018 \\
Accepted Mar 6, 2019 \\
\hline
\end{tabular}

Keywords:

Controller, DC- DC chopper, Hybrid multi converter topology (HMCT),

\begin{abstract}
A hybrid multi converter topology is proposed in this paper, which supplies simultaneous voltage's for various levels from Renewable energy source. The proposed topology is realized by replacing Multi cuk- buck converter topology. The resultant hybrid multi converter requires less number of switches to operate, as well as various output voltages of different levels without interruption with increased stability. This type of hybrid multi converter with high reliability and high stability are well implemented for loads utilizing various levels of DC voltage. Converter, proposed in this paper is called Hybrid Multi converter topology (HMCT). A study is made on the steady state of the HMCT and a comparative study has been made with the conventional designs. A PI controller based feedback controller is designed to stabilize the various output voltages. A simulated model for the proposed HMCT is used to simulate various output voltages of dissimilar values from mono DC- input. The performance of the converter is demonstrated using simulation model. The proposed design can be protracted to voltage source inverter, multilevel inverter to produce AC output.
\end{abstract}

Copyright (C) 2019 Institute of Advanced Engineering and Science. All rights reserved.

\section{Corresponding Author:}

E. Catherine Amala Priya,

Sathyabama Institute of Science \& Technology,

Chennai. India

Email: rahulcathy@gmail.com,

\section{INTRODUCTION}

From past decade renewable energy sources (RES) are playing vital role. Though renewable energy based sources are developing rapidly, many developing nations are still finding some difficulties to avail the source of renewable energy due to various factors like cost, efficiency, difficulty in installing. Developing nations certainly opt for high efficient systems with reduced cost. The proposed hybrid multi converter topology-HMCT has been designed in a manner such that it produces uninterrupted stable output simultaneously at different voltage levels based on the consumer requirement with reduced cost and improved efficiency.

Renewable energy sources are used widely in different applications. Many types of converters are connected along with renewable energy source for serving different industrial and domestic applications [1]. Reference [2] proposes a converter for bipolar DC link based on SEPIC and Cuk to obtain the high voltage with different switching time period. Choppers are extensively used in the area of DC- DC conversion for applications like DC grids [3, 4]. Magnitude of the voltage can be stepped up or stepped down and polarity can be inverted [5]. The converter system has been realized by using pulse width modulation methods [6]. Different converters have been studied from various perspectives, depending upon their gain, amplitude, working, and efficiency. In the literature, converters like Boost, Buck, Buck- Boost, Cuk, Cuk- Sepic have been labeled $[7,8]$. 
The applications of chopper fed inverter $[9,10]$ and grid applications for a single output voltage. Multiple inputs are used to obtain a single DC-DC output which are limited for fewer applications [11-13]. Literature study on conversion stages of DC-DC converter like single stage, three stage conversions have been regarded [14-15]. The boost Converter [16] with modified switching pattern and reduced number of components with improved input power factor is presented. The proposed method is also adopted with bridgeless construction to reduce forward voltage drops of the switches. More over the efficiency and the power factor of converter are improved by the proposed switching pattern which is adopted in PFC chips with the slight modifications. Mainly the thermal stability of the converter circuit is improved with reduced components. In addition, the noise inference and losses associated with switches are the decreased with the proposed switching pattern.

A new integrated three level AC to DC converter [17] fed DC motor with cascaded filter is presented. This converter integrates the operation of the boost power factor correction and the three-level DC-DC converter. This converter is made to operate with two independent controllers-input controllers that performs power factor correction (PFC) and regulates the dc bus and an output controller that regulates the output voltage. The circuit is analyzed for different criterion and the results are presented.

To get a nearer unity power factor, Vienna rectifier [18] is employing the two current control methods. They are (i) Hysteresis current control. (ii) Fuzzy logic control. The combined arrangement of the fixed pitch wind turbine driving a permanent magnet synchronous generator is interfaced with this Vienna rectifier. The rectifier arrangements are used to compare the performance of the proposed converter without any current control methods. The wind speed variations and the constant wind speed conditions are used to study the performance of this converter for the stand alone loads. A simple buck converter [19-20] at the output stage of three phase diode rectifier with bidirectional switches. The buck converter regulates the voltage at the output stage for speed control applications. The fuzzy logic based control method is developed to improving the conduction period of the bi directional switches. The new technique is simulated with DC drive application by PI controller as well as Fuzzy controller and the results are compared.

A Hybrid Multi Converter Topology (HMCT) has been designed exclusively for DC applications with better advantages to overcome the voltage conversion process, stability and to increase the range of applications. Figure 1 shows the Hybrid multi converter topology which consists of a multi Cuk converter and a buck converter. Source to the circuit is fed from the renewable energy source using solar panels. The proposed hybrid multi converter topology can simultaneously produce DC output of various step output voltages.

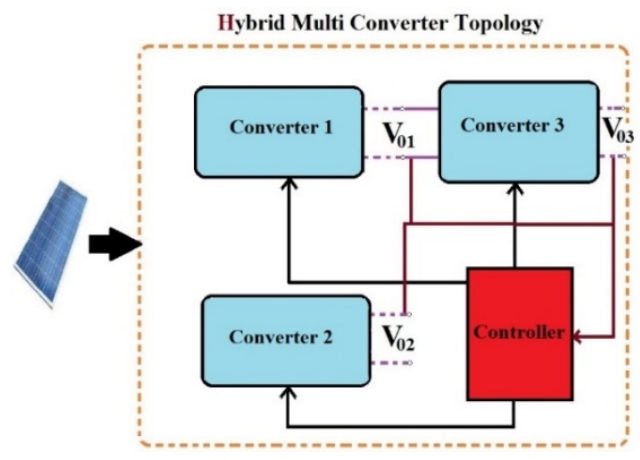

Figure 1. Block diagram of hybrid multi converter topology

Two Different type converters have been implied. Multi Cuk converter produces different outputs higher than the supply voltage. Input voltage produced can be stepped up and high magnitude output voltages can be obtained using Cuk converter. Simultaneously, from converter 3 using buck converter lower voltage can be obtained. Complexity of the proposed system is reduced commendably with simple operation and control technique. One of the advantages is, with a separate switch for each converter synchronization issue can be avoided with a suitable control mechanism. To increases the stability of the system, PI control technique is implemented distinctly each for Cuk \& buck converters. Concurrently manifold output voltages are acquired. Diverse applications based on DC source can be served; industrial applications can be realized with the proposed converter topology where DC motors of dissimilar voltages can be used. Multistep output from mono input RES by means of DC-DC converter has been obtained by modifying the converter topology. The system is explained through locked loop control using MATLAB. The paper is prearranged as 
follows: Part 2 defines the design and development of Hybrid Multi Converter Topology. Part 3 illustrates the results and discussions. Part 4 gives the inferences and conclusions.

\section{PROPOSED TOPOLOGY DESCRIPTION}

The traditional Cuk converter from Figure 2(a) is designed by two inductors $L_{1}$ and $L_{2}$, capacitor $C_{1}$, semiconductor switch $S 1$ and diode $D$. Similarly Buck converter in Figure 2(b) is designed using an inductor $L_{l}$, switch $S_{l}$, diode $D$. The Cuk is designed as a high output converter, while the buck is designed to be a low output converter.

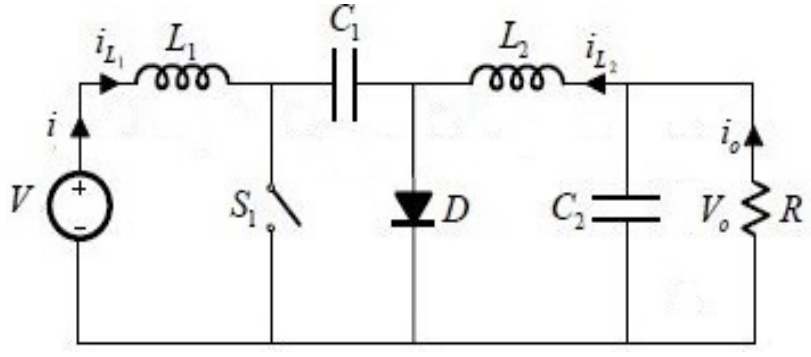

(a)

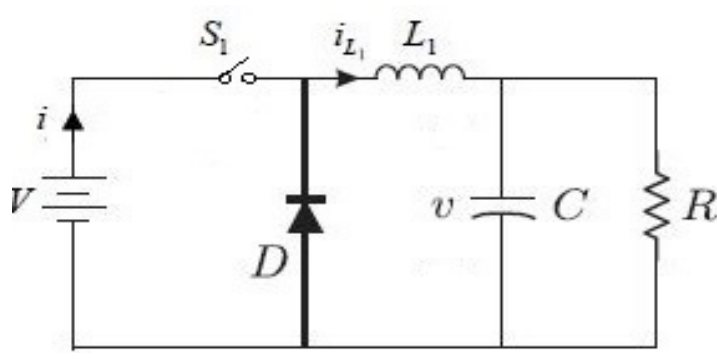

(b)

Figure 2. Cuk and buck converters, (a) cuk converter, (b)buck converter

Continuous conduction mode has been used since it produces better efficiency and effective use of active elements and passive elements.

$$
\begin{aligned}
& V=\frac{|V| D}{(1-D)} \\
& I=\frac{|I| D}{1-D} \\
& V=D|V|
\end{aligned}
$$

$\mathrm{V}=$ Input Voltage; $|\mathrm{V}|=$ Output Voltage; the ratio of duty cycle $(D)$ is given by on time $\left(T_{O N}\right)$ to the total time period $\left(T_{S}\right)$. Cuk and Buck converters, though they have a similar working for varying voltages, they differ with their operation and principle. Cuk converter can invert the polarity and change the magnitude whereas buck converter can modify the output magnitude to a lower level. With a significant combination of Cuk- Buck converters, simultaneous high output voltage and low output voltage with dissimilar values can be accomplished.

From Figure 3, the operation of hybrid multi converter topology, supply from the photo voltaic panels is fed to the circuit. Switch $\mathrm{S}_{1} \& \mathrm{~S}_{2}$ are closed at the same time, the supplied energy will be stored in the inductors $\mathrm{L}_{1}, \mathrm{~L}_{01}$ and $\mathrm{L}_{2}, \mathrm{~L}_{02}$. Alternate to the input and output capacitor $\mathrm{C}$ and $\mathrm{C}_{0}$ are connected; $\mathrm{C}_{1}$ and $\mathrm{C}_{01}$ are also connected in the similar fashion. During the $\mathrm{ON}$ period $\mathrm{L}_{01}$ and $\mathrm{L}_{02}$ store the energy while capacitor $\mathrm{C}$ and $\mathrm{C}_{01}$ discharges. At this time interval, freewheeling diodes, $\mathrm{D} 1$ and $\mathrm{D}_{2}$ are turned off; supplied energy to the loads is delivered by the output capacitors given with $\mathrm{C}_{0}$ and $\mathrm{C}_{01}$. After a while, $\mathrm{S} 1$ and $\mathrm{S}_{2}$ are switched off, capacitors $\mathrm{C}$ and $\mathrm{C}_{01}$ get recharged through inductors by means of freewheeling diodes, $\mathrm{D}_{1}$ and $\mathrm{D}_{2}$. Cuk converter distributes two simultaneous outputs of different voltages. Further, the output from Cuk converter is fed to buck converter. 


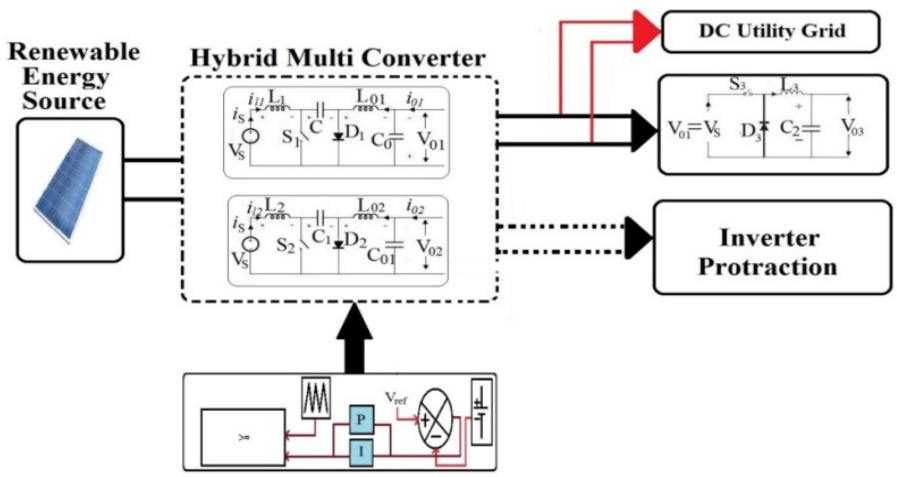

Figure 3. Circuit Diagram of the proposed Hybrid Multi Converter Topology

\subsection{Operation of hybrid multi converter topology}

Converter 1 produces the output voltage $V_{01}$, where $V_{01}>V_{S}$ i.e., obtained output $\left(V_{01}\right)$ will be boosted above the supply voltage $\left(\mathrm{V}_{\mathrm{S}}\right)$. Switch $\mathrm{S} 3$ will be closed in Converter 3 , the output, $\mathrm{V}_{01}$ from Cuk converter will be fed to the buck converter. Buck converter produces extremely a low output. i.e $\mathrm{V}_{03}<\mathrm{V}_{01} \mathrm{In}$ a similar working pattern, the output voltage obtained across converter 2 will be, $V_{02}>V_{S}$. Cuk converter with output voltage $\mathrm{V}_{02}$ is left for a future protraction of inverter. Analysis for Cuk converter,

$$
\begin{aligned}
& D=\frac{T_{\text {on }}}{T} \\
& V_{O 1}=V_{02}=\frac{D}{(1-D)} V_{S} \\
& V_{S}=V_{L 1} \\
& V_{S}=V_{L 2} \\
& \mathrm{P}_{\text {in }}=\mathrm{V}_{\mathrm{S}} \mathrm{I}_{\mathrm{S}}=\frac{D}{(1-D)} V_{S} I_{S} \\
& \mathrm{P}_{\text {out } 1}=\mathrm{V}_{01} \mathrm{I}_{01} \\
& \mathrm{P}_{\text {out2 }}=\mathrm{V}_{02} \mathrm{I}_{02} \\
& I S=\frac{D}{(1-D)} I_{0} \\
& I_{0}=\frac{V_{0}}{R}
\end{aligned}
$$

Analysis for buck converter,

$$
\begin{aligned}
& \mathrm{V}_{01}=\mathrm{V}_{\mathrm{S}} \\
& \mathrm{V}_{03}=\mathrm{D}\left(\mathrm{V}_{01}\right)
\end{aligned}
$$

Equations (4) \& (5) show the analysis and output values of the proposed hybrid multi converter topology. $\mathrm{V}_{01}, \mathrm{~V}_{02}, \mathrm{~V}_{03}$ operate at same time to produce simultaneous output. Depending upon the component values, output of the multi Cuk converter will vary.

\subsection{Operating modes of HMCT}

Figure 4 explains the operation and working characteristics of the proposed hybrid multi converter topology. Mode I: One of the Cuk converter and buck converter are operated, switch $\mathrm{S}_{1}$ is turned on, the converter produces output voltage $V_{01}$ further the output $V_{01}$ is fed to the buck converter, switch $S_{3}$ is turned on which produces output $\mathrm{V}_{03}$. Here, both the converters are operated simultaneously. Mode II: Both the Cuk converters are operated simultaneously, switch $S_{1}$ and $S_{2}$ are turned on which produces output $V_{01}$ and $V_{02}$. Both the Cuk converters are fed with same input voltage whereas they produce a different output. By varying the component (inductor, capacitor) ratings different outputs are obtained. Mode III: In this mode, second 
Cuk converter is operated which produces the output $\mathrm{V}_{02}$. In future the output from Cuk converter two which produces comparatively high output voltage then other converter can be used for the inverter protraction. The complete operation of the proposed hybrid multi converter topology operates in the closed loop mechanism. The control over the circuits is obtained from PI controller for Cuk converter and PI controller for buck converter. Improved efficiency has been observed, $\mathrm{S}_{1}, \mathrm{~S}_{2}, \mathrm{~S}_{3}$, switches are triggered using the control mechanism of analog controllers. The output voltage is fed to the controller and a constant reference voltage set through battery is fed and both are compared. Stable output is produced exactly around the set voltage.

Table 1. Voltage and current equations of HMCT

\begin{tabular}{ccc}
\hline Device performance & Switch & Diode \\
\hline $\begin{array}{c}\text { Average Voltage across the link Capacitors } \\
\text { Average Current across } \\
\text { the Inductors }\end{array}$ & $V \frac{D^{2}}{R}(1-D)^{2}$ & $V \frac{D^{2}}{R}(1-D)$ \\
\hline
\end{tabular}

Table 2. Switching Sequence of Hmct

\begin{tabular}{ccccc}
\hline Modes & $\mathrm{S}_{1}$ & $\mathrm{~S}_{2}$ & $\mathrm{~S}_{3}$ & Output \\
\hline Mode 1 & On & Off & On & $\mathrm{V}_{01}, \mathrm{~V}_{03}$ \\
Mode 2 & On & On & Off & $\mathrm{V}_{01}, \mathrm{~V}_{02}$ \\
Mode 3 & Off & On & Off & $\mathrm{V}_{02}$ \\
Mode 4 & On & On & On & $\mathrm{V}_{01}, \mathrm{~V}_{02}, \mathrm{~V}_{03}$ \\
\hline
\end{tabular}

Average performance values of inductor and capacitor are illustrated in the Table 1. Instead of all switches, an average value is taken for switch and diode crosswise the link capacitor and inductors. A link capacitor and inductor connected crosswise to buck and Cuk converters will have high values to avoid the flow of negative current and to reduce the reverse effect on the converters.

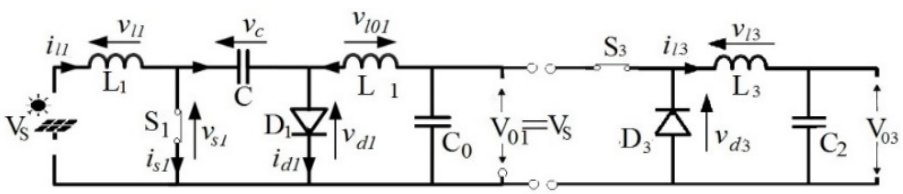

Mode I $\left(\mathrm{S}_{1}\right.$ and $\mathrm{S}_{3}$ turned $\left.\mathrm{ON}\right)$

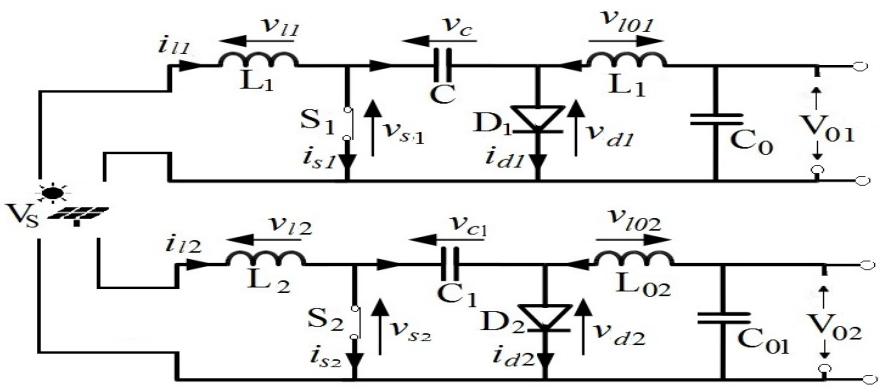

Mode II ( $\mathrm{S}_{1}$ and $\mathrm{S}_{2}$ turned $\left.\mathrm{ON}\right)$

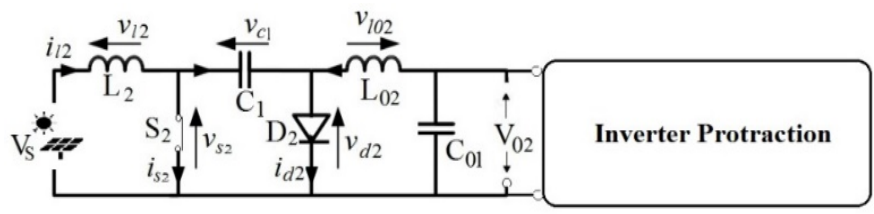

Mode III (S2 turned ON)

Figure 4. Equivalent circuit diagram of HMCT for Various Modes of Operation 


\section{RESULTS \& DISCUSSIONS}

A design of the proposed hybrid multi converter topology has been developed using the software tool. Various results have been simulated. The design of the converter topology has been simulated using MATLAB. Input voltage of $14 \mathrm{~V}$ is given through the Renewable energy source using photo voltaic panel. The input is fed to the circuit is boosted using Cuk converter. Figure 5, shows the different waveforms for boosted voltage obtained from Cuk converter. Waveform portrays three outputs with different voltage. Converter 1 produces $\mathrm{V}_{01}$ Similarly other converter 2 and 3 produces $\mathrm{V}_{02}$ and $\mathrm{V}_{03}$. Overall output ( $\left.\mathrm{V}_{\text {out }}\right)$ obtained from Multi converter stays around $180 \mathrm{~V}$. (i.e. $\mathrm{V}_{02}+\mathrm{V}_{03}=\mathrm{V}_{\text {out }}$ ). Duty Cycle value $\mathrm{D}$ was found to be 0.9 . When output voltage value calculated with respect to duty cycle, the theoretical value is $198.8 \mathrm{~V}$. The difference with the practical value is $18.8 \mathrm{~V}$. $\mathrm{V}_{01}$ voltage obtained from Cuk converter output is fed to the buck converter which ladders down the voltage to lower magnitude value around $10 \mathrm{~V}$.

Table 3. Comparsion of HMCT with conventional converter

\begin{tabular}{ccccc}
\hline $\begin{array}{c}\text { Parameters } \\
\text { operation }\end{array}$ & $\begin{array}{c}\text { [3]- SEPIC; CUK } \\
\text { step up }\end{array}$ & $\begin{array}{c}\text { [4]- BUCK } \\
\text { step down }\end{array}$ & $\begin{array}{c}\text { [13]- Full bridge DC/DC converter } \\
\text { step up }\end{array}$ & $\begin{array}{c}\text { Proposed work- HMCT } \\
\text { step up- step down }\end{array}$ \\
\hline $\begin{array}{c}\text { Switching } \\
\text { Syncronisation }\end{array}$ & No & No & No & Yes \\
Applications & DC & DC & AC & DC with Inverter Protraction \\
Conversion Stages & 1 & 1 & 1 & 3 \\
Number of outputs & 1 & 1 & 1 & 4 \\
Efficiency & $86 \%$ & $83 \%$ & $87 \%$ & $91 \%$ \\
\hline
\end{tabular}

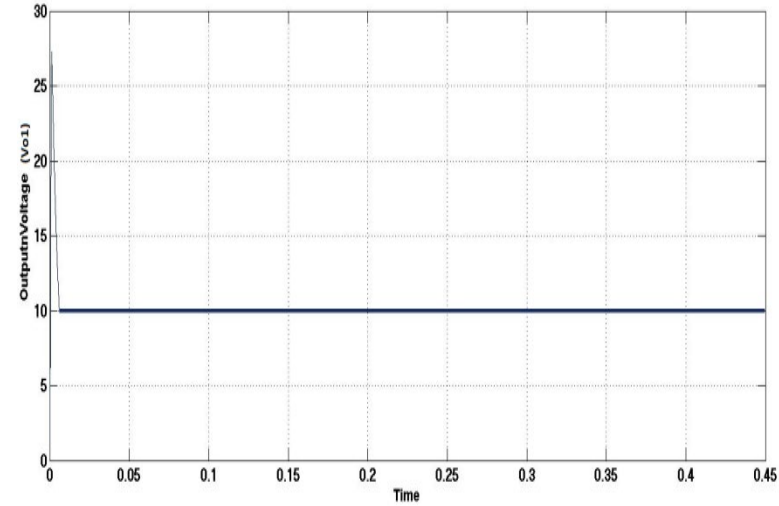

(a)

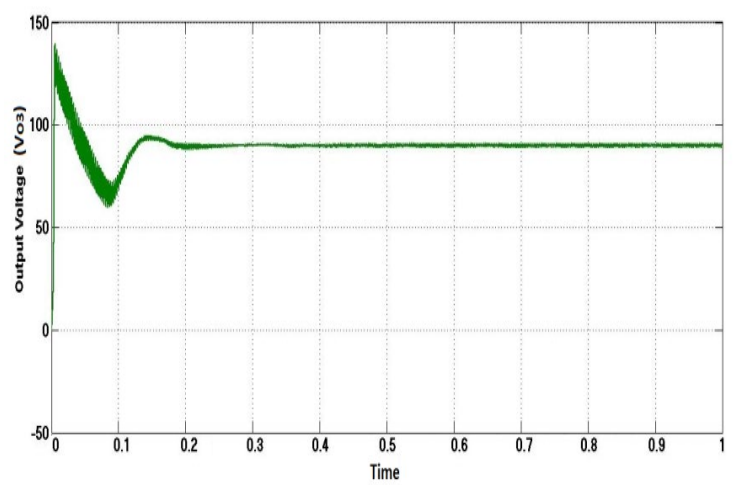

(c)

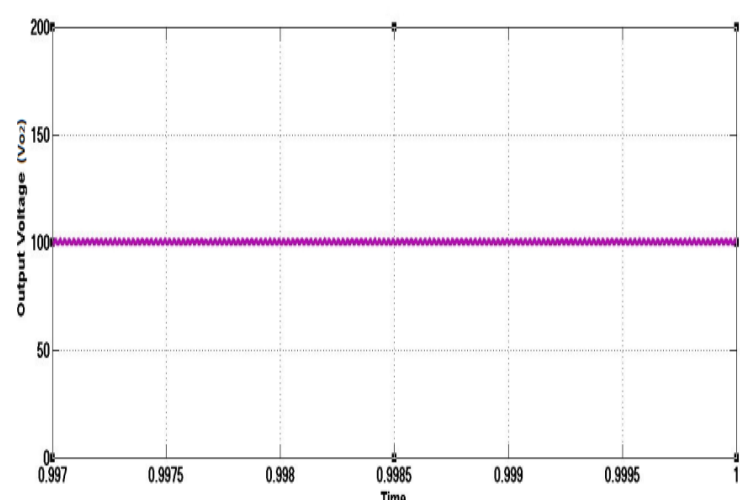

(b)

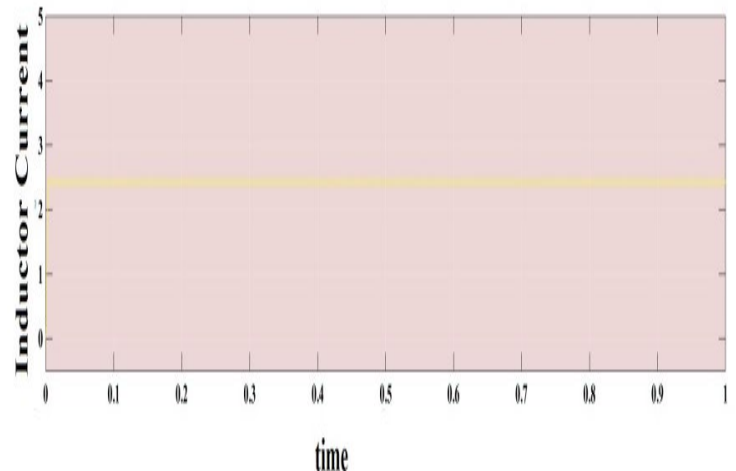

(d)

Figure 5. Voltage and current waveforms from converters, (a) buck output voltage, (b) converter 1 output voltage, (c) converter 2 output voltage, (d). inductor current- converter 1 


\section{CONCLUSION}

Hybrid multi converter topology has been proposed, simulation results have been presented. In the proposed design the multi converters have the identical ratio of voltage conversion. They produce alike output with dissimilar values. Diverse level of voltages has been produced with the design of Hybrid multi converter topology. The prime advantage of the proposed design is accomplished through a mono input multi output system. The dissimilar voltages permit the extensive range of application to get realized. The design produces an enhanced and more cost-effective system with the intake of mono- squat input from renewable energy source. Switching system mechanism works in the same sync which makes the driver system to work more efficiently and effective control system produces controlled output through single control system. Isolation performances have been avoided since the system is maintained stable for both balanced and unbalanced condition which reduces the complexity of the design and economically effective. A protraction port for inverter which can be used for AC applications as future augmentations.

\section{REFERENCES}

[1]. Liyan Qu, Yanping Jiao, Jianwu Zeng, Wei Qiao, "An Isolated Multiport DC-DC Converter for Simultaneous Power Management of Multiple Different Renewable Energy Sources", IEEE Journal Of Emerging And Selected Topics In Power Electronics, Vol. 2, No. 1, pp 70- 74, March 2014

[2]. M.B. Ferrera, S.P. Litrán, E. Durán, J.M. Andújar, “A Converter for Bipolar DC Link Based on SEPIC Cuk Combination”, IEEE Transactions on Power Electronics, vol. 20, no. 3, pp. 662-668, January 2016.

[3]. M.B. Ferrera, S.P. Litrán, E. Durán, J.M. Andújar, "A SEPIC-Cuk Converter Combination for Bipolar DC Microgrid Applications”, IEEE Transactions on Power Electronics, vol. 30, no. 4, pp. 341-345 November 2015

[4]. Ram'on Silva-Ortigoza, Victor Manuel Hern'andez-Guzm'an, Mayra Antonio-Cruz, and Daniel Mũnoz-Carrillo, "DC/DC Buck Power Converter as a Smooth Starterfor a DC Motor Based on a Hierarchical Control", IEEE Transactions On Power Electronics, Vol. 30, No. 2, pp 1076-1081 February 2015

[5]. M. Ortega, F. Jurado, Senior Member, IEEE and D. Vera, "Novel Topology for DC-DC Full-Bridge Unidirectional Converter for Renewable Energies", IEEE Latin America Transactions, vol. 12, no. 8, pp 1381- 1385, December 2014.

[6]. Huawu Liu, Haibing $\mathrm{Hu}$, Hongfei Wu, Yan Xing, Issa Batarseh, "Overview of High-Step-Up Coupled-Inductor Boost Converters", IEEE Journal of Emerging and Selected Topics in Power Electronics, vol. 10, no. 1, pp. 650654, July 2016.

[7]. Arun Shastry P S, Suresh K V, Vinayaka K U, "Hybrid Wind-Solar Systems using Cuk-SepicFused Converter with Quasi-Z-Source Inverter", 2015 IEEE Power, Communication and Information Technology Conference (PCITC), 2015.

[8]. J.M. Maza-Ortega A. Go' mez-Expo' sito M. Barraga' n-Villarejo E. Romero-Ramos A. Marano-Marcolini, "Voltage source converter-based topologies to further integrate renewable energy sources in distribution systems", IET Renewable Power Generation, 5th April 2012.

[9]. Bin Wu, Shouxiang Xiang, Yao Liu and, Keyue Smedley, "A New Hybrid Boosting Converter (HBC) for Renewable Energy Applications", IEEE Transactions on Power Electronics, vol. 03, no. 14, pp. 202-207, 2015.

[10]. Serkan Dusmez, Xiong Li, and Bilal Akin, "A New Multi-Input Three-Level DC/DC Converter", IEEE Transactions on Power Electronics, 2015.

[11]. Khaligh, J. Cao, and Y.-J. Lee, "A Multiple-Input DC-DC Converter Topology," IEEE Trans Power Electron., vol. 24, no. 3, pp. 862-868, Mar. 2009

[12]. Y. Li, X. Ruan, D. Yang, F. Liu, and C. K. Tse, "Synthesis of Multiple-Input DC/DC Converters," IEEE Trans Power Electron., vol. 25, no. 9, pp. 2372-2385, Sept. 2010.

[13]. K. Dwarakesh, A. Vishnu Kumar, "Rechargeable Vehicle Accusing Technique For Clever Home Erection With A Photovoltaic System," International Journal of Pure and Applied Mathematics. vol. 119, no. 12, pp. 4775-4784, Dec. 2018.

[14]. S. Danyali, S.H. Hosseini, and G. B. Gharehpetian, "New extendable single stage multi-input DC-DC/AC boost converter," IEEE Trans. Power Electron., vol. 29, no. 2, pp. 775-788, Feb. 2014

[15]. S. Dusmez, X. Li, and B. Akin, "A Fully Integrated Three-Level Isolated Single-Stage PFC Converter," IEEE Trans Power Electron, vol. 30, no. 4, pp. 2050-2062, Apr. 2015.

[16]. V. Senthil Nayagam, G. T. Sundar Rajan and V. Balasubramanian, "Improved Power Factor at Input Stage of Pseudoboost Rectifier with Improved Switching Pattern", International Journal of Applied Engineering Research, Volume 10, Number 6, pp. 5158 - 5164, 2015.

[17]. R.Hemaprithni and G.T.Sundar Rajan, "Three Level Integrated AC to DC Converter fed DC Drive with Cascaded filter", International Journal of Applied Engineering Research, Volume 10, Number 6, pp. 5140 - 5146, 2015.

[18]. D. Jayanthy, G.T.Sundar Rajan, "A Novel Unity Power Factor At Input Stage Of Vienna Rectifier For Wind Energy Conversion System Using Fuzzy Logic", International Journal of Applied Engineering Research, Volume 10, Number 6, pp. $5650-5655,2015$.

[19]. G. T. Sundar Rajan and C. Christober Asir Rajan, "A Novel Unity Power Factor Input Stage With Resonant DC Link Inverter for AC Drives”, Journal of Electrical Engineering, Volume 12 / 2012 - Edition: 4, pp. 62 - 66, 2012. 
[20]. G. T. Sundar Rajan and C. Christober Asir Rajan, "Fuzzy Inference System Based Power Factor Correction of Three Phase Diode Rectifier using Field Programmable Gate Array", American Journal of Applied Sciences, Volume 10 - Issue 9 / 2013, pp. 986-999.

\section{BIOGRAPHIES OF AUTHORS}

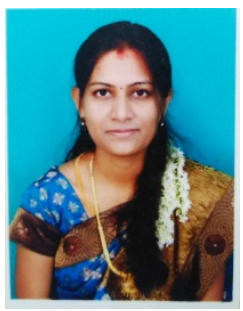

E.Catherine Amala Priya has Master's degree in Power Electronics and Industrial Drives from Anna University. She topped the University during her Master's and was recipient of the prestigeous "Gold Medal" from Mr.Jeppiaar. She has good experience of 5+ years in teaching subjects related to Electrical \& Electronics Engineering at Jeppiaar Engineering college \& Achariya College of Engineering \& Technology. She has published \& presented numerous papers in international/national forums. She is presently pursuing Ph.D. from Sathyabama University. Areas of her interest are power quality improvement, harmonics reduction, AC and DC drives.

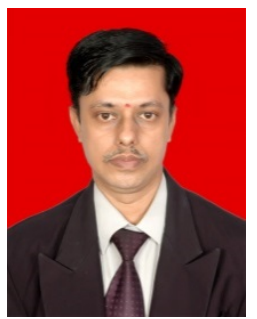

G. T. Sundar Rajan born in Tirunelveli District, Tamilnadu State, India in 1975, received B.E. degree in Electrical and Electronics Engineering from the University of Madras and the M.E. degree in Power Electronics and Industrial Drives and Ph. D. from the Sathyabama University, Chennai, India in 1997, 2007 and 2014 respectively. He has published technical papers in international and national journals and conferences. Presently he is working as an Associate Professor in the Department of EEE at Sathyabama Institute of Science and Technology, Chennai. He has a total teaching experience of 18 years. His areas of interest are power quality improvement, harmonics reduction, $\mathrm{AC}$ and $\mathrm{DC}$ drives. 